\title{
THE EVALUATION OF ENDURANCE IMPROVEMENT IN THE TRANSITION PERIOD
}

\author{
Gaetano RAIOLA ${ }^{1 *}$, Tiziana D’ISANTO² ${ }^{\text {, Francesca D'ELIA }}{ }^{1}$, Gaetano ALTAVILLA ${ }^{3}$ \\ ${ }^{1}$ University of Salerno, Salerno, Italy \\ ${ }^{2}$ MIUR Campania, Italy \\ ${ }^{3}$ University of Split, Split, Croatia \\ *Corresponding author: graiola@unisa.it
}

DOI: $10.35189 /$ iphm.icpesk.2019.38

\begin{abstract}
Soccer is a sport with wide popularity in Italy. The aim of the study was to analyse and evaluate the performance decrease or improvement in two groups of 12 male soccer players aged 13-14 years (group A and group B). Group A continues the training sessions during the transition period, while group $B$ does not continue the workouts. The study method is experimental. The tests applied to young soccer players are easy to administer and are intended to investigate two different characteristics of endurance, namely general and specific endurance. The data were collected over eight weeks (during the transition period). All the collected data were expressed as average $\pm S D$ for height, weight, body mass index (BMI) and the Cooper test. The statistical analysis of data involves using the Student's t-Test to assess the performance of the two groups in the transition period (June-September) and between the two groups in September. The significant differences were set at $p<$ 0.05. The results show that there is a significant difference between the two groups in September. For group B (that does not continue the training during the transition period), there is no significant difference, while for group A (that continues the training during the transition period), there is a significant difference. The analysis and evaluation of the performance decrease or improvement allow coaches to monitor the training process and design the training load for effective performance.
\end{abstract}

Keywords: soccer, quantitative aspects, Cooper test, training programme, performance.

\section{Introduction}

The period of time from the end of the championship until September is generally defined as the transition period (Forte \& Altavilla, 2018). The transition period is an important phase, which usually allows for physical and psychological recovery through complete rest, with the suspension or decrease (in intensity, volume and frequency) of physical activity (D'Elia, D'Isanto, \& Altavilla, 2019). Soccer enjoys wide popularity in Italy and many sports associations and schools promote it. Soccer is a sport with high agonistic commitment, which requires the development of all conditional abilities (Raiola \& Rago, 2014; Cirillo, Nughes, Acanfora, Altavilla, \& D'Isanto, 2016) and the acquisition of general and specific motor skills (D'Isanto, Manna, \& Altavilla, 2017). Among the various physical qualities needed, we can mention the ability to perform straight-line sprinting and positive and negative acceleration (di Prampero et al., 2005) with rapid changes of directions, often called agility (Mathisen \& Svein, 2015), but also the endurance ability. In recent years, players run faster, perform technical skills with higher speed and make better tactical decisions (Alizadeh, Hovanloo, \& Safania, 2010). Coaches and any person involved in the training of young soccer players should take into account aspects such as the distance travelled in order to design specific drills (Altavilla, Riela, Di Tore, \& Raiola, 2017).

This study involves using the Cooper test, which is easy to administer and can detect the characteristics of endurance. Endurance is one of the conditional abilities representing the structural prerequisite for the execution of any sporting gesture and is related to the concept of fatigue. There are various types of exercises that can be distinguished on the basis of their intensity and duration and therefore we will have to do with specific characteristics of endurance (Jones \& Carter, 2000), which are related to the involvement of different (aerobic and anaerobic) mechanisms of ATP resynthesis. We will also have to do with general (or basic generic) endurance, which refers to the player's aerobic qualities, and specific endurance, which, in addition to aerobic qualities, refers to anaerobic qualities that are particularly linked to lactic acid metabolism. The aim of the study was to analyse and evaluate the performance decrease or improvement in two groups of 12 male soccer players aged 13 to 14 years, who performed physical and anthropometric tests at the end of the regular season and the beginning of the next one. 


\section{Material and Methods}

The study method is experimental, and the data were collected over eight weeks (during the transition period). The survey was carried out on two groups of 12 males aged 13 to 14 years (group A and group B), who performed physical and anthropometric tests at the end of the regular season and the beginning of the next one (Table 1).

Table 1. Anthropometric data

\begin{tabular}{lrl}
\hline Group A $(\mathrm{n}=12)$ & \multicolumn{1}{c}{ M } & SD \\
\hline Age $($ year $)$ & 13.9 & 3.7 \\
Height $(\mathrm{cm})$ & 158.1 & 5.1 \\
Weight $(\mathrm{Kg})$ & 51.6 & 7.1 \\
BMI $\left(\mathrm{Kg} / \mathrm{m}^{2}\right)$ & 20.7 & 1.2 \\
\hline
\end{tabular}

\begin{tabular}{lrr}
\hline Group B $(\mathrm{n}=12)$ & \multicolumn{1}{c}{ M } & SD \\
\hline Age (year) & 14.1 & 3.9 \\
Height $(\mathrm{cm})$ & 160.2 & 4.2 \\
Weight $(\mathrm{Kg})$ & 52.8 & 4.3 \\
BMI $\left(\mathrm{Kg} / \mathrm{m}^{2}\right)$ & 20.6 & 1.4 \\
\hline
\end{tabular}

The physical test is easy to administer, does not require special equipment and is useful for quickly obtaining information on large populations; due to its simplicity, it is often used for assessments in youth sectors. The test performed by the young players is the Cooper test, which investigates maximum aerobic power and maximum aerobic speed. It is a very popular test, which consists of running for 12 minutes to cover the longest distance possible. The result is given by the distance travelled (Cooper, 1968). It is a power test, because there is a significant relationship between the distance travelled in 12 minutes and maximum aerobic power (expressed in $\mathrm{mL} / \mathrm{kg} / \mathrm{min})$.

The test was performed by 12 young soccer players from a soccer school in the category of "teenagers" aged between 13 and 14 years. The test took place on a 7-a-side soccer field measuring 65 meters long and 40 meters wide. Furthermore, because they were minors, parents signed a written agreement accepting to take responsibility and authorise their children to perform the Cooper test. After a comprehensive presentation about the way of conducting the test and its usefulness, the subjects performed the endurance test.

All the collected data were expressed as average \pm SD for height, weight, body mass index (BMI) and the Cooper test, and the normality of distribution (KS Test) was checked. The analysis involves using the Student's tTest to assess the performance of the two groups in the transition period (June-September) and between the two groups in September. The significant differences were set at $p<0.05$. All statistical analyses were conducted using the Dell 13.2 statistical software.

\section{Results}

The performance of the two groups in the transition period (June-September) and between the two groups in September is shown in Tables 2 and 3.

Table 2. Cooper test-Group A (June)

Cooper test-Group B (June)

\begin{tabular}{lccc|lccc}
\hline & $\begin{array}{c}\text { Distance } \\
\text { covered }(\mathrm{m})\end{array}$ & $\begin{array}{c}\text { Time spent } \\
(\mathrm{min} \text { per } \mathrm{km})\end{array}$ & VO2max & & $\begin{array}{c}\text { Distance } \\
\text { covered }(\mathrm{m})\end{array}$ & $\begin{array}{c}\text { Time spent } \\
(\mathrm{min} \text { per km })\end{array}$ & VO2max \\
\hline 1 & 2100 & 2.71 & 35.66 & 1 & 2100 & 2.71 & 35.66 \\
2 & 2520 & 4.76 & 45.05 & 2 & 2100 & 2.71 & 35.66 \\
3 & 2520 & 4.76 & 45.05 & 3 & 2520 & 4.76 & 45.05 \\
4 & 2940 & 4.08 & 54.43 & 4 & 2520 & 4.76 & 45.05 \\
5 & 2730 & 4.39 & 49.74 & 5 & 2730 & 4.39 & 49.74 \\
6 & 3150 & 3.8 & 59.13 & 6 & 3150 & 3.8 & 59.13 \\
7 & 2520 & 4.76 & 45.05 & 7 & 2520 & 4.76 & 45.05 \\
8 & 3150 & 3.8 & 59.13 & 8 & 3150 & 3.8 & 59.13 \\
9 & 2100 & 2.71 & 35.66 & 9 & 2520 & 4.76 & 35.66 \\
10 & 3150 & 3.8 & 59.13 & 10 & 3150 & 3.8 & 59.13 \\
11 & 2730 & 4.39 & 49.74 & 11 & 2730 & 4.39 & 49.74 \\
12 & 3150 & 3.8 & 59.13 & 12 & 3150 & 3.8 & 59.13 \\
Average & 2730 & 3.98 & 49.74 & Average & 2695 & 4.04 & 48.18 \\
\hline \multicolumn{7}{c}{248} &
\end{tabular}


International Proceedings of Human Motricity/ ICPESK 2019

Supplementary Issue of Discobolul - Physical Education, Sport and Kinetotherapy Journal, 2019

Table 3. Cooper test - Group A (September) C Cooper test - Group B (September) $\backslash$

\begin{tabular}{lccc|cccc}
\hline & $\begin{array}{c}\text { Distance } \\
\text { covered }(\mathrm{m})\end{array}$ & $\begin{array}{c}\text { Time spent } \\
(\text { min per km) }\end{array}$ & VO2max & & $\begin{array}{c}\text { Distance } \\
\text { covered }(\mathrm{m})\end{array}$ & $\begin{array}{c}\text { Time spent } \\
(\text { min per km) }\end{array}$ & VO2max \\
\hline 1 & 2520 & 4.76 & 45.05 & 1 & 2100 & 2.71 & 35.66 \\
2 & 2520 & 4.76 & 45.05 & 2 & 2100 & 2.71 & 35.66 \\
3 & 2730 & 4.39 & 49.74 & 3 & 2520 & 4.76 & 45.05 \\
4 & 2940 & 4.08 & 54.43 & 4 & 2520 & 4.76 & 45.05 \\
5 & 2730 & 4.39 & 49.74 & 5 & 2730 & 4.39 & 49.74 \\
6 & 3150 & 3.8 & 59.13 & 6 & 2940 & 4.08 & 54.43 \\
7 & 2730 & 4.39 & 49.74 & 7 & 2520 & 4.76 & 45.05 \\
8 & 3150 & 3.8 & 59.13 & 8 & 2940 & 4.08 & 54.43 \\
9 & 2520 & 4.76 & 45.05 & 9 & 2520 & 4.76 & 35.66 \\
10 & 3150 & 3.8 & 59.13 & 10 & 2940 & 4.08 & 54.43 \\
11 & 2940 & 4.08 & 54.43 & 11 & 2730 & 4.39 & 49.74 \\
12 & 3150 & 3.8 & 59.13 & 12 & 2940 & 4.08 & 54.43 \\
Average & 2852.5 & 4.23 & 52.48 & Average & 2625 & 4.13 & 46.61 \\
\hline \multicolumn{7}{r}{} \\
\hline
\end{tabular}

The results shown in Table $6(\mathrm{p}=0.03)$ indicate that there is a significant difference between the two groups in September. For group B (that does not continue the training during the transition period), there is no significant difference, as shown in Table $5(\mathrm{p}=0.50)$, while for group A (that continues the training during the transition period), there is a significant difference, as shown in Table $4(\mathrm{p}=0.02)$. The analysis and evaluation of the performance decrease or improvement allow coaches to monitor the training process and design the training load for effective performance.

Table 4. Difference in the Cooper test between June and September for group A

\begin{tabular}{ll}
\hline \multicolumn{1}{c}{ t-Test for group A (difference June - September) } \\
\hline p-value & 0.02 (Significant) \\
significance level & $\alpha=0.05$ \\
\hline
\end{tabular}

Table 5. Difference in the Cooper test between June and September for group B

\begin{tabular}{ll}
\hline \multicolumn{2}{c}{ t-Test for group B (difference June - September) } \\
\hline p-value & 0.50 (Insignificant) \\
significance level & $\alpha=0.05$ \\
\hline
\end{tabular}

Table 6. Difference between the two groups for the Cooper test

\begin{tabular}{ll}
\hline \multicolumn{1}{c}{ Independent t-Test for groups A and B (final difference in September) } \\
\hline p-value & 0.03 (Significant) \\
significance level & $\alpha=0.05$ \\
\hline
\end{tabular}

\section{Discussion and Conclusion}

The data of this study confirm the hypothesis that an excessive transition period leads to a decrease in performance. Statistical data processing showed that group A (that continued the training sessions during the transition period, namely over eight weeks) recorded a significant improvement between June and September ( $p=$ 0.02); instead, group B (that did not continue the training sessions during the transition period), had no significant improvement between June and September $(\mathrm{p}=0.50)$. Also, group A had a significant improvement (with $\mathrm{p}=$ 0.03 ) compared to group B at the end of the transition period (September). The test is a tool that allows a very effective periodic control and, through the analysis of its results and the feedback received, it is possible to relate 
performance to the work strategies adopted. Therefore, with this operational strategy, it is possible to identify the best adaptations to be made to the training programme administered to athletes. In order to optimise monitoring and programming, this study should be repeated several times during the competitive season (preparation phase) to periodically check whether there are improvements in the physical and technical performance. Each club should invest more in this transition period. At the end of the competitive season, it is essential to plan and limit the "stop" of the players in order to avoid a decrease in their physical condition. This solution would then allow those involved in physical training to avoid having such problems (D’Elia, Mazzeo, \& Raiola, 2018).

In this study, we aimed to present a very practical evaluation method that can make us reflect on the training proposals that need to be developed. Programming must be the result of the functional evaluation of the young athlete. The next step will be to define the modulation of loads during programming to fill in the highlighted gaps or even to further improve the players' best qualities.

The conclusion drawn is an invitation to further investigations in order to reach the scientific knowledge that must always be the basis of any training methodology.

\section{References}

Alizadeh, R., Hovanloo, F., \& Safania, A. M. (2010). The relationship between aerobic power and repeated sprint ability in young soccer players with different levels of $\mathrm{VO}_{2}$ max. Journal of Physical Education and Sport,

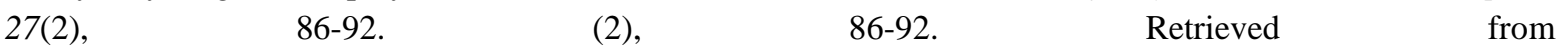
http://www.efsupit.ro/images/stories/imgs/JPES/2010/2/MicrosoftWord-13.pdf

Altavilla G., Riela L., Di Tore P. A., \& Raiola G. (2017). The physical effort required from professional football players in different playing positions, Journal of Physical Education and Sport, 17(3), 2007-2012. Retrieved from https:/www.questia.com/library/journal/1P4-1980701303/the-physical-effort-required-fromprofessional-football

Cirillo, G., Nughes, E., Acanfora, A., Altavilla, G., \& D’Isanto, T. (2016). Physical and sport education testing by quantitative and qualitative tools in assessment in senior school: A proposal. Sport Science, 9(Suppl. 1), 97101. Retrieved from https://www.cabdirect.org/cabdirect/abstract/20163259149

Cooper, K. H. (1968). A means of assessing maximal oxygen uptake. JAMA, 203(3), 201-204. doi: 10.1001/jama.1968.03140030033008

D’Elia, F., D'Isanto, T., \& Altavilla, G. (2019). Training and performance in the transition period, Journal of Human Sport \& Exercise, 14(2), 258-262. https://doi.org/10.14198/jhse.2019.14.Proc2.15

D'Elia, F., Mazzeo, F., \& Raiola, G. (2018). The core curriculum in the university training of the teacher of physical education in Italy. Journal of Human Sport and Exercise, 13(2), 413-420. https://doi.org/10.14198/jhse.2018.13.Proc2.25

D’Isanto, T., Manna, A., \& Altavilla, G. (2017). Health and physical activity. Sport Science, 10(1), $100-105$. Retrieved from https://www.sposci.com/PDFS/BR1001/SVEE/04\%20CL\%2018\%20TD.pdf

di Prampero, P. E., Fusi, S., Sepulcri, L., Morin, J. B., Belli, A., \& Antonutto, G. (2005). Sprint running: A new energetic approach. The Journal of Experimental Biology, 208, 2809-2816. https://doi.org/10.1242/jeb.01700

Forte, D., \& Altavilla, G. (2018). Preliminary correlation between anthropometric and performance data in volleyball about the transition period, Journal of Physical Education and Sport, 18(Suppl. 5), 1994-1998. DOI: 10.7752/jpes.2018.s5296

Jones, A. M., \& Carter, H. (2000). The effect of endurance training on parameters of aerobic fitness. Sports Medicine, 29(6), 373-386. https://doi.org/10.2165/00007256-200029060-00001

Mathisen, G., \& Svein, A. P. (2015). The effect of speed training on sprint and agility performance in female youth soccer players. Journal of Physical Education and Sport, 15(3), 395-399. DOI: 10.7752/jpes.2015.03059

Raiola, G., \& Rago, V. (2014). Preliminary study on effects of HIIT-high intensity intermittent training in youth soccer players. Journal of Physical Education and Sport, 14(2), 148-150. DOI: 10.7752/jpes.2014.02023 